\title{
LA SITUACIÓN MODAL DE LAS COMPLETIVAS DE INFINITIVO EN PLAUTO
}

This paper is a structuralistic study of the modal character of infinitive object clauses in Plautus, in comparison with alternative formulae such $u t+$ subjunctive or quod. Having demonstrated that object clauses with quod occur only rarely in Plautus, the paper focuses on the pair $u t+$ subjunctive and accusative + infinitive. A detailed analysis of the Plautine corpus reveals a systematic use of $u t+$ subjunctive for object clauses of notional content and helps to confirm the basic hypothesis of the study, namely that infinitive clauses in Plautus are used to cover the semantic area of non-notional object clauses. A numeric comparison of these two constructions and the study of the functional relationship between them is the primary aim of the paper, the main conclusion of which is the proposal of the structure $u t+$ subjunctive object clauses / infinitive object clauses (left area positive), following the basic concept of fiction or absence of fiction.

1. Al estudiar recientemente' las oraciones completivas introducidas por $u t$ en Plauto y comprobar la absoluta regularidad del modo subjuntivo en las mismas, habíamos recordado las siguientes palabras de Rubio: «el modo subjuntivo en las subordinadas que estudiamos no plantea problemas (...). Se trata de procesos intencionales, deseados o supuestos, (y) nadie se extraña de que esas oraciones excluyan el indicativo o modo de la realidad y utilicen en cambio el subjuntivo" (Rubio, 1982, p. 309).

$\mathrm{Y}$ encontrábamos, en efecto, un considerable número de completivas con $u t$ - concretamente 742 - cuyo subjuntivo hacía referencia a hechos aún no realizados y de cuya realidad, por tanto, no podía responderse.

1 Cf. nuestra tesis doctoral «Estructura de la categoría verbal 'modo' en Plauto", Sevilla 1985. Actualmente se halla publicada la parte que versa sobre la oración independiente (La categoria verbal modo en Plauto, Sevilla 1986) y está en vías de publicación una segunda parte sobre la subordinación (El modo en la subordinación plautina. Estudio funcional). 
2. Esta exclusión del uso del indicativo en la subordinación con ut - deciamos en su momento que por razones de simplificación morfosintáctica - nos hizo pensar en distintas formalizaciones sintácticas para las completivas de carácter no eventual. Pero la conjunción quod apenas si servia para tal cometido completivo todavía en Plauto - hablaremos más adelante de su extensión mucho más tardía (Lindsay, 1936 , p. 112, y Bennett, 1966, pp. 125 y 318) -, donde sólo contamos con una decena de ejemplos; eso sí, todos con indicativo y lejos de cualquier tipo de ficción o eventualidad.

$\mathrm{Y}$, en efecto, esta será la tónica modal predominante durante algunos siglos; pues si bien las completivas con quod nunca han excluido al modo subjuntivo (Rubio, 1982, p. 328), lo cierto es que, salvo razones particulares de sentido o construcción (Bennett, 1966, p. 318, y ErnoutThomas, 1964, p. 295), se reconoce en todos los tiempos un uso indiscutiblemente mayoritario del indicativo.

3. Había que pensar, pues, en una alternativa sintáctica clara para las oraciones con $u t$ capaz de cubrir el campo significativo de las completivas no eventuales ${ }^{2}$. Y no nos quedaba más remedio - las interrogativas indirectas tenian otra modalidad de frase suficientemente diferenciadora - que indagar en el mismo seno de esa otra construcción tan literaria (Perrochat, 1932, p. 18, y Bassols, 1976, II, p. 208) y $\tan$ latina (Bennett, 1966, p. 366; Hahn, 1950, p. 117, y Rubio, 1982, p. 169): las completivas de infinitivo.

Así las cosas, sólo nos resta confirmar lo que a estas alturas ya se habrá entendido como nuestra hipótesis de trabajo; a saber:

- las completivas con $u t$ parecen cubrir el campo específico de lo eventual (contenidos de tipo fictivo, impresivo, etc.);

- y las completivas del más puro ámbito de lo real se van a servir masivamente de la construcción infinitiva (apenas podemos contar con quod en este temprano autor).

La medida de ambas construcciones y la relación funcional entre una y otra constituirán el objetivo fundamental de estas breves páginas. Y no cabe hablar de esa controvertida sinonimia sintáctica - en la que casi sólo creen ya los más empedernidos generativistas - porque las diferenciaciones - y no sólo de matiz o estilísticas - se dejan ver (lo demostraremos con ejemplos y con los datos completos de Plauto) con claridad suficiente.

Atisbos de nuestra hipótesis se leen ya, por ejemplo, en la Sintaxis

2 Y precisamente el infinitivo subordinado - por razones de organización interna - había quedado excluido del trabajo a que haciamos referencia en la nota 1. 
de Ernout-Thomas, que advierten el doble sentido de algunos verbos: declarativo - y se construían con oración de infinitivo- o voluntativo -y entonces utilizaban ut $(1964$, p. 303$)$.

Las excepciones a todo ello salen al paso sin dificultad porque «declarativo" y "voluntativo" no son los únicos contenidos oracionales que se enfrentan; sabemos que en la sintaxis declarativa caben mensajes variados: reales, sólo posibles o del todo irreales. Así que convendrá tener en cuenta estas matizaciones modales si se quiere ofrecer una explicación completa del asunto.

4. Pero echemos una ojeada al panorama bibliográfico: explicaciones tradicionales, últimas aportaciones...

Las más conocidas sintaxis han centrado su atención en los verbos regentes y no en la naturaleza de los mensajes expresados en la subordinada. Es así como nos presentan «fatigosas listas» (Rubio, 1982, p. 317) de verbos capaces de introducir completivas con $u t$, con quod o de infinitivo; listas que, de hecho, suelen coincidir en gran parte para los tres tipos (Bennett, 1966, p. 367; Ernout-Thomas, 1964, pp. 296 y 321, y Bassols, 1976, II, pp. 182 y 192) y desde luego no exentas de excepciones.

Hace ya algunos años que Bolkestein encontraba dificultades insalvables para este tipo de distinciones basadas en los verbos regentes: algunos dicendi (negare, promittere) regian siempre acusativo con infinitivo; otros (iubere) infinitivo o $u t$ sin diferencia de significado; otros (dicere, suadere) ambas construcciones con diferencia de significado; y los impérandi, en fin, usaban una u otra indistintamente (Bolkestein, Mnemosyne, 1976, p. 159).

Pero ¿cuál es exactamente el estado de la cuestión tal y como ha llegado a nuestras manos?

4.1. Nos encontramos con un quod, de expansión sólo tardía y sobre todo vulgar (Lindsay, 1936, p. 112; Bennett, 1966, p. 125, y Bassols, 1976, II, p. 192), que al parecer introduce completivas de circunstancias realizadas y que, por tanto, suelen ir en indicativo (Ernout-Thomas, 1964, p. 295). La decena de ejemplos plautinos a que aludíamos más arriba nos ratifica tales afirmaciones teóricas.

4.2. Muy otra es la situación sintáctica que se descubre en las completivas encabezadas por $u t$, que, de ser en un principio coordinadas de indole volitiva o deliberativa (Bassols, 1976, II, p. 181), polarizaron su contenido hacia el campo de lo impresivo (Rubio, 1982, p. 320). Ya hemos visto que esta explicación tradicionalmente admitida silenciaba las importantes diferenciaciones modales entre lo real y lo fictivo.

4.3. La construcción de infinitivo, en fin, que hasta la época impe- 
rial no va a sufrir la dura concurrencia de las con quod (Bassols, 1976, II, p. 208), parece ser de uso común en cualquier época, si bien sólo adquirió un desarrollo sintáctico adecuado - sobre todo para la expresión de los modos - a partir de época clásica (Perrochat, 1932, p. 75; Ernout-Thomas, 1964 , p. 326, y Bassols, 1976, II, p. 216) y comenzó entonces a resultar artificiosa y compleja para el lenguaje coloquial (Perrochat, 1932, p. 18).

La tradición sintáctica nos muestra esta construcción de infinitivo como poco marcada - menos, en todo caso, que la de $u t$ y subjuntivo (Bolkestein, Mnemosyne, 1976, p. 162) - y encaminada ca si sólo hacia contenidos declarativos (Ernout-Thomas, 1964, pp. 320-321, y Bolkestein, Mnemosyne, 1976, p. 162), sin que se descarte su presencia - siempre débil - entre lo impresivo o volitivo (Ernout-Thomas, 1964, p. 328 , y Bassols, 1976, II, p. 220).

5. Nos queda por buscar el contenido específico de cada uno de los tipos y su interrelación sistemática. En definitiva, explicar la aparente sinonimia de no pocos ejemplos (oraciones de infinitivo con contenido no declarativo) y la radical diferencia de la mayoría (lo declarativo y el infinitivo frente a lo no declarativo y $u t$ ).

Y vamos a hacerlo - imposible de otra manera - desde una perspectiva a la vez teórica (dentro del más puro estructuralismo) y práctica (ofreciendo datos concretos, los extraidos del conjunto de la obra plautina).

Habíamos mencionado ya los 742 ejemplos de ut con subjuntivo para contenidos completivos alejados de la realidad lingüistica (órdenes, deseos, posibilidades, irrealidades...) y una dudosa presencia de quod - con indicativo - que daba cuenta de hechos realmente ocurridos. Pues bien, las comedias de Plauto nos proporcionan además un total de 1.887 mensajes completivos a base de oraciones de infinitivo. Pero ¿de qué clase de mensajes se trata? La minuciosa observación de los textos y contextos, ejemplo a ejemplo, no ha tardado en descubrirnos que una mayoría significativa de los mismos - 1.408 - pertenecen al ámbito lingüístico de lo real (mejor ya abandonar la más confusa denominación de "declarativo»). Sirvan de ejemplo:

Am. 500 menses iam tibi esse actos uides.

Am. 562 audes mihi praedicare id, domi te esse nunc...?

As. 352 dico me $<\mathrm{d}>$ esse atriensem.

As. 926 uxorem me esse meministi tuam?

Au. 60-61 scelestiorem me hac anu certo scio uidisse numquam...

$\mathrm{Ba} . \mathbf{4 5 6}$ saluum te aduenire gaudeo.

Ba. 1096 uxorem esse aiebat. 
Cap. 587 scio te id nolle fieri.

Cas. 564 stultitia magna est..., hominem amatorem ullum ad forum procedere.

Cu. 555 quid refert me facisse...?

Ep. 383 non... modo homines aequum fuit sibi habere speculum.

Men. 1040 me negant eum esse.

Men. 1095 Menaechmum, ..., te uocari dixeras.

Mer. 771 uerum illud uerbum esse experior...

Mo. 905-6 nusquam edepol ego me scio uidisse umquam obiectas aedes.

Poe. 557 non meminisse nos ratu's...

St. 585 saluum gaudeo peregre te in patriam rediisse.

Los $465^{3}$ que introducen por el contrario objetos oracionales supuestos, deseados o, en cualquier caso, todavía no demostrados (en la línea de:

As. 296 iubeo te saluere uoce summa.

Ba. 1062 nolo ego mihi credi.

Ci. 717 hanc scire oportet...

Mer. 272 ego illunc hircum castrari uolo...

Mo. 328 sine cadere me.

Pe. 181 ire decet me...

Ps. 468 cupis me esse nequam.

Tru. 585 desiccari iube.),

no son más que los legítimos usos neutros de la estructura que a continuación proponemos:

completivas con $u t+$ subj./completivas de infinit.

(zona izquierda positiva) según la noción básica de ficción o ausencia de ficción; justificación estructural casi innecesaria en este caso, pues no es casualidad en esta azarosa selección la presencia constante de verbos regentes modales - o asimilables a ellos-, de comportamiento sintáctico - como sabemos - en muchos sentidos independiente.

Claro que con los regentes de voluntad (como impero) el infinitivo las más de las veces es un simple objeto directo nominal (Bolkestein, Mnemosyne, 1976, pp. 284-285). Y, en efecto - así nos lo hace ver Bolkestein - , la diferencia entre dico eum uenire («digo que viene») y dico ut ueniat («le digo que venga»), donde se enfrentan un mensaje aseverativo y otro fictivo, no es comparable a la establecida entre impero eum uenire e impero ut ueniat, donde uenire puede interpretarse como un simple sustantivo, objeto directo del verbo principal, en cuyo caso no

3 Sólo hay 14 textos de dudosa interpretación por razones de contaminación semántica, subdependencia, estilo indirecto... 
cabría hablar de oración de infinitivo; hasta el punto de poder sólo admitirse con seguridad tal construcción en el caso de los infinitivos pasivos (Bassols, 1976, II, p. 220). Con ello reduciriamos también el número de usos neutros (pese a que aun sin tal reducción la estructura parece suficientemente integrada).

Y parece que no debe hablarse de que $u t$ haya servido para introducir mensajes declarativos - al menos no ha sido así en Plauto - completando expresiones del tipo uerum est ut y similares. Son Ernout-Thomas los responsables de tal afirmación, mientras que en los escasos ejemplos que aducen no resulta difícil entender contenidos del todo eventuales:

- Cic., Pomp. 62: quid tam inusitatum quam ut... eques Romanus... pro consule mitteretur? ("iqué hay tan inusual como el hecho de que un caballero romano sea enviado en calidad de procónsul?»).

- Cic., N. D. I 63; de dis neque ut sint, neque ut non sint habeo dicere («acerca de los dioses no puedo decir ni que existan ni que no existan»).

Los mismos autores, en fin, líneas más abajo, reconocen ya en expresiones como uerisimile est ut un subjuntivo justificado por la idea de duda.

6. El reparto funcional era tan claro en Plauto que no hacía falta introducir sofisticadas distinciones modales en el seno del mismo infinitivo. Sólo más adelante, con la extensión del quod completivo en este mismo terreno real y la paralela postergación del infinitivo subordinado a lo literario, habría lugar para tales artificiosidades sintácticas.

\section{Concepción Fernández Martínez}

\section{BIBLIOGRAFIA}

Bassols, M., Sintaxis latina, II, Madrid 1976 (=1956).

Bennett, Ch. E., Syntax of early latin, I, Hildesheim $1966(=1910)$.

Bolkestein, A. M., "A. c. i. and ut-clauses with uerba dicendi in Latin", Glotta 54, 1976, pp. 263-291.

- «The differences between free and obligatory ut-clauses», Glotta 55, 1977, pp. 231-250.

- "The relation between form and meaning of Latin subordinate clauses governed by uerba dicendi), Mnemosyne 29, 1976, pp. 155-175 y 268-301.

Ernout, A., y Thomas, F., Syntaxe latine, Paris 1964.

Hahn, E. A., "Genesis of the Infinitive with subject Accusative», TAPhA 81, 1950, pp. 117-129.

Lindsay, W. M., Syntax of Plautus, Nueva York 1936 (=1907).

Perrochat, P., Recherches sur la valeur et l'emploi de l'infinitif subordonné en latin, - París 1932.

Ronconi, A., Il verbo latino. Problemi di sintassi storica, Florencia 1959.

Rubio, L., Introducción a la sintaxis estructural del latín, Barcelona 1982. 